\title{
Assessment of anxiety-depression levels and perceptions of quality of life in adolescents with dysmenorrhea
}

\author{
Nilfer Sahin ${ }^{1^{*}}$ (D) Burcu Kasap ${ }^{2}$, Ulviye Kirli ${ }^{3}$, Nese Yeniceri ${ }^{4}$ and Yasar Topal ${ }^{3}$
}

\begin{abstract}
Background: This study aimed to assess the anxiety-depression levels and the perceptions of quality of life, as well as the factors affecting these variables, in adolescents with dysmenorrhea.

Methods: The participants included 60 adolescents with dysmenorrhea and 41 healthy adolescents between the ages of 12 and 18. This study used the Pediatric Quality of Life Inventory (PedsQL) for assessing the perceptions of quality of life, the State-Trait Anxiety Inventory (STAI) for measuring anxiety levels, and the Children's Depression Inventory (CDI) for measuring depression levels.

Results: It was determined that compared to healthy controls, the depression and anxiety scores were higher and the quality of life was impaired in adolescents with dysmenorrhea. In addition, it was shown that the depression and anxiety levels increased and the psychosocial health subscale scores of quality of life decreased with increasing dysmenorrhea severity. However, the likelihood of dysmenorrhea was found to be higher with increasing depression scores, while the anxiety levels had no effect on dysmenorrhea.
\end{abstract}

Conclusion: In dysmenorrhea management, it is important to enhance awareness among pediatric clinicians and gynecologists regarding the associations between dysmenorrhea and mental problems.

Keywords: Dysmenorrhea, Anxiety, Depression, Quality of life

\section{Plain english summary}

This study aimed to assess the anxiety-depression levels and the perceptions of quality of life, as well as the factors affecting these variables, in adolescents with dysmenorrhea.

The participants included 60 adolescents with dysmenorrhea and 41 healthy adolescents between the ages of 12 and 18. This study used the Pediatric Quality of Life Inventory (PedsQL) for assessing the perceptions of quality of life, the State-Trait Anxiety Inventory (STAI) for measuring anxiety levels, and the Children's Depression Inventory (CDI) for measuring depression levels.

It was determined that compared to healthy controls, the depression and anxiety scores were higher and the quality of life was impaired in adolescents with

\footnotetext{
* Correspondence: nilfersahin@hotmail.com

'Department of Child and Adolescent Psychiatry, Mugla Sitki Kocman

University, School of Medicine, 48000 Mugla, Turkey

Full list of author information is available at the end of the article
}

dysmenorrhea. In addition, it was shown that the depression and anxiety levels increased and the psychosocial health subscale scores of quality of life decreased with increasing dysmenorrhea severity. However, the likelihood of dysmenorrhea was found to be higher with increasing depression scores, while the anxiety levels had no effect on dysmenorrhea.

In conclusion, in dysmenorrhea management, it is important to enhance awareness among pediatric clinicians and gynecologists regarding the associations between dysmenorrhea and mental problems.

\section{Background}

Dysmenorrhea is a common gynecological problem characterized by pain at the abdominal and lumbar regions within the first few days of menstrual cycle, which limits daily activities of women. It is classified into two groups as primary and secondary dysmenorrhea. Primary dysmenorrhea is defined as cramps originating from the 
uterus during menstruation without any underlying pelvic pathology, while secondary dysmenorrhea is defined as menstrual pain resulting from underlying pelvic pathologies such as endometriosis [1]. Dysmenorrhea may be accompanied by headache, nausea, vomiting and fatigue. In adolescents, primary dysmenorrhea is seen in normal ovulatory cycles without any pelvic pathology. Its incidence has been reported as $60-93 \%$ in adolescents worldwide [2,3], while studies in Turkey have reported an incidence of $55.5-70.0 \%$ among adolescents and young adults $[4,5]$.

Dysmenorrhea can affect the mental health and social life of an individual. Prior studies have shown that women with dysmenorrhea often fail to go to work or school, resulting in an impaired quality of life. The rate of absence days from school was reported to vary between $14 \%$ and $51 \%$ among women with dysmenorrhea [6]. Additionally, the rate of class attendance was reported to decrease by $29-50 \%$ during dysmenorrhea periods. Studies on adults report that a lower perception of quality of life among women with dysmenorrhea [7].

It is known that there is a close relation between pain and depression. The prevalence of headache or neckshoulder pain is high in depression, while depression prevalence is high in patients with chronic pain syndromes [8]. Many studies have shown that depression enhances the effect of pain on social and occupational functionality and decreases the likelihood of response to medical therapy [9]. Moreover, anxiety levels were found to be higher in patients with migraine or other types of headaches [10]. It is thought that the levels of anxiety and depression, which have been found to be associated with many types of pain, are also associated with dysmenorrhea. Emotional and behavioral problems increase menstrual cycle problems and dysmenorrhea. A study on adolescents showed that anxiety, depression and smoking have an influence on dysmenorrhea [11]. Although advances have been achieved in the studies on the pathophysiology of dysmenorrhea, the association between gynecological and psychological factors has not yet been fully established. Currently, dysmenorrhea cannot be controlled in many cases, despite the availability of various treatments. Therefore, to achieve effective treatment, it is important to identify the factors that may affect the severity of dysmenorrhea and its comorbidities.

Previous studies have generally focused on adult women and there is a limited number of studies on the relationship between dysmenorrhea and mental problems, and its effect on the quality of life during adolescence. The present study aimed to assess the anxiety-depression levels and the perceptions of quality of life, as well as the factors affecting these variables, in adolescents with dysmenorrhea.

\section{Methods}

The study included 60 adolescents between the ages 12 and 18 who presented at the Obstetrics and Gynecology and the Pediatric outpatient clinics of Muğla Sitkı Koçman University, Faculty of Medicine, with dysmenorrhea between January 2015 and July 2015. Patients with mental retardation hampering communication and those with comorbid chronic diseases were excluded from the study. The control group included 41 adolescent girls of similar age and education level without any psychiatric and chronic disorders who were admitted at the Pediatric outpatient clinic.

All participants were asked to complete a demographic data sheet with questions on age, educational status, academic success, age at menarche, time from the onset of dysmenorrhea and duration of dysmenorrhea, family history of dysmenorrhea and measures taken during painful periods. The academic achievement levels of the cases were determined as good, modarate and bad, according to their declarations. The severity of dysmenorrhea was classified according to what they did for pain during the dysmenorrhea episodes (those who applied hot packs or used pain killer were evaluated as mild-moderate, those who applied emergency department were evaluated as severe dysmenorrhea). This study used the Pediatric Quality of Life Inventory (PedsQL) for assessing the perceptions of quality of life, State-Trait Anxiety Inventory (STAI) for measuring anxiety levels and Children's Depression Inventory (CDI) for measuring depression levels.

The study was approved by the Ethics Committee on Scientific Research and Publications of Muğla Sitk1 Koçman University (approval date: 04.07.2014). All participants and their parents provided a written informed consent in accordance with the Helsinki Declaration.

\section{Data Collection Tools.}

Pediatric Quality of Life Inventory (PedsQL): The scale was developed by Varni et al. in 1999 to measure the health-related quality of life of children and adolescents aged between 2 and 18 years [12]. The scale consists of seven forms including parent forms for children or adolescents aged $2-4,5-7,8-12$ and $13-18$ years, and selfreport forms for children or adolescents aged 5-7, 8-12 and 13-18 years. The scale assesses the prior month of children and adolescents. It includes 23 items. Scoring is performed in three domains. Total score is obtained by summing the psychosocial health summary score and the physical health summary score, which in turn are obtained by adding the scores for the items assessing emotional, social and school functions. A higher total score indicates a better perception of the quality of life. 
The reliability and validity study for the Turkish version of the scale was conducted by Memik et al. [13].

Children Depression Inventory (KOVACS-CDI): This scale was developed by Kovacs in 1980 [14]. It is a selfreport questionnaire including 27 items, and is applied to children and adolescents between the ages of 6 and 17 . The cut-off value is 19 and the highest possible total score is 54 points. A higher total score indicates severe depression. It was adapted to Turkish by Oy in 1991 [15].

State-Trait Anxiety Inventory (STAI): This scale was developed by Spielberger [16]. The Turkish reliability and validity study of the scale was conducted by Öner et al. [17]. It consists of two scales, which are a traitanxiety and a state-anxiety scale. Both scales include 20 items rated using a 4-point Likert scale. The traitanxiety scale assesses how an individual generally feels, independently of the conditions involved. The stateanxiety scale assesses how an individual feels at a certain moment. The scores range from 20 to 80 in each scale. Higher scores indicate increased anxiety levels.

\section{Statistical analysis}

Statistical analyses were performed using the SPSS for Windows version 20.0 (Statistical Package for Social Sciences Inc., Chicago, USA). The Student's t test was used to compare the variables with normal distribution, while Mann Whitney $U$ test was used to compare the data with skewed distribution. Chi-square test was used to compare categorical variables. Continuous variables were presented as descriptive statistics such as mean \pm standard deviation. When assessing the associations between sociodemographic characteristics, clinical data and the scores of the patient and the control groups, the Pearson correlation analysis was used for parametric data, whereas Spearman's correlation analysis was used for non-parametric data. To determine the effects of measures taken during menstrual period on scores, the Kruskal-Wallis test was used for the variables with normal distribution, whereas one-way ANOVA test was used for data with skewed distribution. Logistic regression analysis was used to assess the effects of scores on dysmenorrhea. A $p$ value $<0.05$ was considered as statistically significant.

\section{Results}

In our study, the mean age was $15.46 \pm 1.38$ in the dysmenorrhea group and $15.24 \pm 1.47$ in the control group. The mean age at menarche was $12.65 \pm 1.13$ in the dysmenorrhea group and $12.75 \pm 0.85$ in the control group. When educational status was considered, it was observed that $78.3 \%$ of the patients in the dysmenorrhea group were at high school, while $21.7 \%$ were at secondary school. In the control group, $65.9 \%$ of the patients attended high school, while $34.1 \%$ were at secondary school. When academic success was considered, it was found that $61.7 \%$ of the patients in the dysmenorrhea group reported as having good academic success, while $38.3 \%$ reported moderate academic success. In the control group, $48.8 \%$ reported good academic success, while $51.2 \%$ reported moderate academic success. When the time from the onset of dysmenorrhea was evaluated in the dysmenorrhea group, it was found to be $23.68 \pm$ 15.90 months, while the mean duration of dysmenorrhea was determined as $2.56 \pm 1.49$ days. In the dysmenorrhea group, there was history of dysmenorrhea in $63.3 \%$ of the patients with dysmenorrhea in the mother in $48.3 \%$ and in sister in $15.0 \%$. When measures taken against dysmenorrhea were evaluated, it was found that $53.3 \%(n=32)$ have taken painkillers, that $28.3 \%(n=11)$ have visited emergency service, and that $18.3 \%(\mathrm{n}=11)$ have used hot packs. In the dysmenorrhea group, $41.7 \%$ had a day of absence from school. There were no statistically significant differences between the patient and control groups in terms of demographic data $(p>0.05)$.

Based on the scores obtained from the data collection tools, the distribution of the PedsQL, STAI-T STAI-S scores were found normal, while physical health and psychosocial health summary scores showed a skewed distribution. The mean score of total PedsQL was 63.60 \pm 8.98 in the dysmenorrhea group and $79.67 \pm 9.37$ in the control group (p: 0.000). The median value of physical health summary score of PedsQL in the dysmenorrhea group was 62.50 , while in the control group it was 75.62 (p:0.000). The median value of psychosocial health summary score of PedsQL in the dysmenorrhea group was 66.66 , while in the control group this value was 83.33 (p:0.000). The mean score of STAI-T in the dysmenorrhea group was $38.18 \pm 11.15$, while this value was $32.46 \pm 6.30$ in the control group (p:0.004). The mean score of STAI-S in the dysmenorrhea group was $47.70 \pm 10.00$. In the control group, this value was 40.36 \pm 6.80 (p: 0.024 ). The median score of CDI was determined as 14 in the dysmenorrhea group, which was 8 in the control group (p:0.000). The differences between the two groups in terms of scale scores were statistically significant (Table 1).

When the correlation of age, age at menarche, time from the onset of dysmenorrhea and duration of dysmenorrhea with the scale scores was examined in the dysmenorrhea group; it was found that the scale scores had no correlation with age, age at menarche and time from the onset of dysmenorrhea $(p>0.05)$, while the total PedsQL score was negatively correlated with the duration of dysmenorrhea ( $\mathrm{r}:-0.284, \mathrm{p}: 0.028)$, and the CDI was positively correlated with the duration of dysmenorrhea (r:0.255, p: 0.049) (Table 2). 
Table 1 Scores in dysmenorrhea and control groups

\begin{tabular}{llll}
\hline & $\begin{array}{l}\text { Dysmenorrhea group } \\
\text { Mean } \pm \text { SD } \\
\text { Median (min-max) }\end{array}$ & $\begin{array}{l}\text { Control group } \\
\text { Mean } \pm \text { SD } \\
\text { Median (min-max) }\end{array}$ & $p$ \\
\hline Total PedsQL & $63.60 \pm 8.98$ & $79.67 \pm 9.37$ & 0.000 \\
PHSS & $62.50(15.62-81.25)$ & $75.62(53.75-100)$ & 0.000 \\
PSHSS & $66.66(41.60-83.33)$ & $83.33(60-98.33)$ & 0.000 \\
STAI-T & $38.18 \pm 11.15$ & $32.46 \pm 6.30$ & 0.004 \\
STAI-S & $47.70 \pm 10.00$ & $40.36 \pm 6.80$ & 0.024 \\
CDI & $14(4-36)$ & $8(3-20)$ & 0.000
\end{tabular}

PedsQL Pediatric Quality of Life Inventory, PHSS Physical health summary score, PSHSS Psychosocial health summary score, STAI-T Trait anxiety inventory, STAI$S$ State anxiety inventory, $C D I$ Children Depression Inventory, $p$ significance value

When scores were considered according to the measures taken during dysmenorrhea, a significant difference was found in scores other than the total and physical health summary scores of PedsQL in cases visiting emergency department compared to those using painkillers or hot packs (Table 3).

When effects of depression and anxiety on dysmenorrhea were considered, the STAI-T and STAI-S scores were found to have no effect on dysmenorrhea, while one-point increase in CDI score caused an increase in the likelihood of dysmenorrhea by $0.194 \quad$ (p:0.006) (Table 4).

\section{Discussion}

Our study, which assessed depression and anxiety levels as well as perceptions of quality of life in adolescents

Table 2 Associations between scores and demographic variables in the dysmenorrhea group

\begin{tabular}{|c|c|c|c|c|c|}
\hline & & Age & $\begin{array}{l}\text { Age at } \\
\text { menarche }\end{array}$ & $\begin{array}{l}\text { Time from onset of } \\
\text { dysmenorrhea }\end{array}$ & $\begin{array}{l}\text { Duration of } \\
\text { dysmenorrhea }\end{array}$ \\
\hline \multirow{2}{*}{$\begin{array}{l}\text { Total } \\
\text { PedsQL }\end{array}$} & $\mathrm{R}$ & -0.26 & -0.46 & 0.06 & -0.284 \\
\hline & P & 0.843 & 0.727 & 0.649 & 0.028 \\
\hline \multirow[t]{2}{*}{ PHSS } & $\mathrm{R}$ & -0.57 & -0.111 & 0.204 & -0.137 \\
\hline & P & 0.666 & 0.399 & 0.119 & 0.296 \\
\hline \multirow[t]{2}{*}{ PSHSS } & $\mathrm{R}$ & -0.052 & 0.008 & -0.12 & -0.214 \\
\hline & P & 0.692 & 0.954 & 0.927 & 0.100 \\
\hline \multirow[t]{2}{*}{ CDI } & $\mathrm{R}$ & 0.114 & 0.097 & -0.070 & 0.255 \\
\hline & P & 0.255 & 0.336 & 0.593 & 0.049 \\
\hline \multirow[t]{2}{*}{ STAI-T } & R & 0.141 & 0.149 & 0.033 & 0.234 \\
\hline & $P$ & 0.160 & 0.138 & 0.803 & 0.072 \\
\hline \multirow[t]{2}{*}{ STAI-S } & r & 0.140 & 0.153 & -0.140 & 0.239 \\
\hline & $p$ & 0.162 & 0.127 & 0.286 & 0.066 \\
\hline
\end{tabular}

Spearman-Pearson correlation analysis

PedsQL Pediatric Quality of Life Inventory, PHSS Physical health summary score, PSHSS Psychosocial health summary score, STAI-T Trait anxiety inventory, STAI$S$ State anxiety inventory, $C D I$ Children Depression Inventory, $p$ significance value, $r$ correlation coefficient
Table 3 Associations between scores and measures taken during dysmenorrhea

\begin{tabular}{|c|c|c|c|c|}
\hline & $\begin{array}{l}\text { Measures taken during } \\
\text { dysmenorrhea }\end{array}$ & Mean \pm SD & $\mathrm{F}$ & $p$ \\
\hline \multirow[t]{3}{*}{$\begin{array}{l}\text { Total } \\
\text { PedsQL }\end{array}$} & Emergency department visit & $\begin{array}{l}60.17 \pm \\
8.75\end{array}$ & 1.857 & 0.164 \\
\hline & Pain killer & $\begin{array}{l}65.27 \pm \\
9.21\end{array}$ & & \\
\hline & Hot packs & $\begin{array}{l}64.05 \pm \\
7.804\end{array}$ & & \\
\hline \multirow[t]{3}{*}{ PHSS } & Emergency department visit & $\begin{array}{l}63.23 \pm \\
12.90\end{array}$ & 0.727 & 0.468 \\
\hline & Pain killer & $\begin{array}{l}62.01 \pm \\
12.06\end{array}$ & & \\
\hline & Hot packs & $\begin{array}{l}57.23 \pm \\
17.72\end{array}$ & & \\
\hline \multirow[t]{3}{*}{ PSHSS } & Emergency department visit & $\begin{array}{l}58.99 \pm \\
11.74\end{array}$ & 4.143 & 0.021 \\
\hline & Pain killer & $\begin{array}{l}67.26 \pm \\
8.98\end{array}$ & & \\
\hline & Hot packs & $\begin{array}{l}67.47 \pm \\
10.47\end{array}$ & & \\
\hline \multirow[t]{3}{*}{ CDI } & Emergency department visit & $\begin{array}{l}24.11 \pm \\
6.35\end{array}$ & 38.49 & 0.000 \\
\hline & Pain killer & $\begin{array}{l}12.15 \pm \\
3.52\end{array}$ & & \\
\hline & Hot packs & $\begin{array}{l}11.54 \pm \\
5.42\end{array}$ & & \\
\hline \multirow[t]{3}{*}{ STAI-T } & Emergency department visit & $\begin{array}{l}47.00 \pm \\
11.07\end{array}$ & 9.986 & 0.000 \\
\hline & Pain killer & $\begin{array}{l}34.00 \pm \\
9.31\end{array}$ & & \\
\hline & Hot packs & $\begin{array}{l}36.72 \pm \\
8.85\end{array}$ & & \\
\hline \multirow[t]{3}{*}{ STAI-S } & Emergency department visit & $\begin{array}{l}55.05 \pm \\
8.45\end{array}$ & 8.215 & 0.001 \\
\hline & Pain killer & $\begin{array}{l}44.25 \pm \\
8.80\end{array}$ & & \\
\hline & Hot packs & $\begin{array}{l}46.36 \pm \\
10.16\end{array}$ & & \\
\hline
\end{tabular}

PedsQL Pediatric Quality of Life Inventory, PHSS Physical health summary score, PSHSS Psychosocial health summary score, STAI-T Trait anxiety inventory, STAI$S$ State anxiety inventory, $C D I$ Children Depression Inventory, $p$ significance value

Table 4 Effects of CDI, STAI-T ad STAI-S on likelihood of dysmenorrhea

\begin{tabular}{lll}
\hline & $\beta$ & $p$ \\
\hline CDI & 0.194 & $\mathbf{0 . 0 0 6}$ \\
STAI-T & -0.019 & 0.928 \\
STAI-S & 0.027 & 0.499 \\
\hline $\begin{array}{l}\text { CDI Children Depression Inventory, STAl-T Trait anxiety inventory, STAI-S State } \\
\text { anxiety inventory, } p \text { significance value }\end{array}$ &
\end{tabular}


with dysmenorrhea, found that, compared to healthy controls, the depression and anxiety scores were higher and the quality of life was lower in adolescents with dysmenorrhea. In addition, it was shown that the depression and anxiety levels increased and the psychosocial health subscale scores of quality of life decreased with increasing severity of dysmenorrhea. While the likelihood of dysmenorrhea was found to increase with increasing depression scores, it was observed that anxiety levels had no effect on dysmenorrhea.

In our study, no significant difference was identified between the dysmenorrhea and control groups with respect to the age at menarche and academic success. There are a number of studies indicating a correlation between age at menarche and dysmenorrhea; however, there are also studies indicating no significant differences $[18,19]$. It is known that dysmenorrhea decreases academic success by causing days of absence from school. Our study found no significant difference in academic success, although, compared to the control group, the scores of psychosocial health summary and quality of life were significantly lower in adolescents with dysmenorrhea. In dysmenorrhea group, academic success was expected to be poorer compared to the control group, since the rate of absence days from school was $41.7 \%$ in this group. Although our study is in agreement with previous studies indicating that dysmenorrhea causes days of absence from school [20], our study differs from those reporting that dysmenorrhea is associated with decreased academic success. It is believed that this difference might have stemmed from the fact that we used self-assessments for evaluating academic success, rather than objective data such as grade average. This, in fact, represents a limitation of the current study.

Many studies have shown that menstrual symptoms are associated with mental status. In a recent study, depression, aggression, insomnia, daytime sleepiness and sleep apnea scores were significantly higher in the dysmenorrhea group than in normal controls [21]. In a study with 400 post-menarche women between the ages of 14 and 20, anxiety and depression scores were found higher in women with dysmenorrhea [22]. It is thought that dysmenorrhea disrupts healthy physical and mental development in adolescence by impairing the quality of life with increased days of absence from school [11], although the mechanism underlying the relationship between dysmenorrhea and psychological problems has not yet been fully elucidated. The association of anxiety and depression with dysmenorrhea can be explained as the adverse effect of chronic pain on mental health. It is known that psychiatric problems, mainly depression, are more common in patients with chronic pain. A study investigating the relationship between personality traits and dysmenorrhea in 49 women found that higher neuroticism-anxiety and depression levels were associated with dysmenorrhea. The same study also emphasized that chemicals such as prostaglandins, vasopressin and phospholipids released during menstrual pain are also associated with depression and anxiety [23]. In agreement with previous studies, our study identified increased levels of depression and anxiety. In addition, depression was found to have a more prominent effect on dysmenorrhea than anxiety when the effects of depression and anxiety on dysmenorrhea were considered, suggesting that adolescents with higher depression scores are predisposed to dysmenorrhea. The finding of increased depression and anxiety levels in cases with dysmenorrhea leads to two questions: whether dysmenorrhea itself impairs an individual's mental health by affecting social life, or whether dysmenorrhea is more commonly seen in individuals with higher levels of anxiety and depression. In our study, the finding of higher anxiety and depression scores in cases with dysmenorrhea suggests that dysmenorrhea itself impairs mental health; however, when the presence of dysmenorrhea was assessed in cases with high depression and anxiety scores, the likelihood of dysmenorrhea was found to be higher in cases with high depression scores. In other words, it was shown that the likelihood of dysmenorrhea was not more common in cases with high anxiety levels. This finding is inconsistent with previous studies reporting a significant effect of anxiety on pain [24].

The studies assessing the perception of quality of life in women with dysmenorrhea have shown that dysmenorrhea impairs the perception of quality of life. In our study, all scores from the quality of life scales were lower in cases with dysmenorrhea compared to the control group. In a study on 623 university students from Turkey, Ünsal et al. evaluated the incidence of dysmenorrhea and the perception of quality of life. Authors showed that the quality of life was impaired by increased severity of dysmenorrhea [7]. In another study that assessed the quality of life during the menstrual period, where there were complaints of dysmenorrhea, and during the follicular phase, where there was no pain in women with dysmenorrhea, it was determined that the perception of quality of life was impaired during the menstrual period [25]. Although the perception of quality of life was found to be poorer in the dysmenorrhea group compared to the control group in our study, it will be more valuable to assess the quality of life during dysmenorrhea and the interictal period in a way similar to the abovementioned study in order to determine the effects of dysmenorrhea on the quality of life, given that the duration of dysmenorrhea is generally $2-3$ days with a longer interictal period. Our study determined that psychosocial health summary score of PedsQL was lower in cases visiting emergency department during 
dysmenorrhea compared to those using painkillers or hot packs. This suggests that the severity of dysmenorrhea affects the quality of life. In our study, anxiety and depression scores were also found higher in cases visiting emergency department during dysmenorrhea compared to those using painkillers or hot packs. In other words, the anxiety and depression scores increased with increasing severity of pain. It is anticipated that increased severity of pain will lead to negative effects on mental health which, in turn, would lead to increased days of absence from school, poorer academic success and impaired quality of life.

Nonetheless, there are certain limitations to this study. Its cross-sectional design and small sample size are the main limitations. We believe that further studies with larger sample size are needed to clarify the relationship between mental health and dysmenorrhea. The lack of the psychiatric examination and a semi-structured interview was evaluated as one of the major limitations of our study.

\section{Conclusion}

In conclusion, it was determined that, compared to the healthy controls, the anxiety and depression levels were higher and the perception of the quality of life was lower in adolescents with dysmenorrhea. It was found that increasing severity of dysmenorrhea further increased the extent of impairment in mental health and the perception of psychosocial health. The likelihood of dysmenorrhea was shown to be higher among cases with higher levels of depression. In dysmenorrhea management, it is important to enhance awareness among pediatric clinicians and gynecologists regarding the associations between dysmenorrhea and mental problems. It is believed that better results can be achieved in the management of dysmenorrhea cases, and that the quality of life can be further improved, by referring the child to a psychiatrist whenever necessary and through psychiatric follow-up.

\section{Abbreviations}

CDI: Children Depression Inventory; PedsQL: Pediatric Quality of Life Inventory; PHSS: Physical health summary score; PSHSS: Psychosocial health summary score; STAI-S: State anxiety inventory; STAI-T: Trait anxiety inventory

\section{Acknowledgements}

Not applicable.

\section{Competing interests.}

The authors declare that they have no competing interests.

\section{Funding}

Not applicable.

\section{Availability of data and materials.}

The datasets used and analyzed during the current study available from the corresponding author on reasonable request.

\section{Authors' contributions.}

NS designed the paper. BK, UK, NY and YT collected the data together. All authors were involved in the organization of the first or subsequent drafts and provided feedback on the drafts. All authors read and approved the final draft.

Consent for publication

Not applicable.

Ethics approval and consent to participate.

The study was approved by the Ethics Committee on Scientific Research and Publications of Muğla Sıtkı Koçman University (approval date: 04.07.2014).

\section{Publisher's Note}

Springer Nature remains neutral with regard to jurisdictional claims in published maps and institutional affiliations.

\section{Author details}

${ }^{1}$ Department of Child and Adolescent Psychiatry, Mugla Sitki Kocman University, School of Medicine, 48000 Mugla, Turkey. ${ }^{2}$ Department of Obstetrics and Gynecology, Mugla Sitki Kocman University, School of Medicine, Mugla, Turkey. ${ }^{3}$ Department of Pediatrics, Mugla Sitki Kocman University, School of Medicine, Mugla, Turkey. ${ }^{4}$ Department of Family Medicine, Mugla Sitki Kocman University, School of Medicine, Mugla, Turkey.

Received: 11 August 2017 Accepted: 7 January 2018

Published online: 26 January 2018

\section{References}

1. Harel Z. Dysmenorrhea in adolescents and young adults: an update on pharmacological treatments and management strategies. Expert Opin Pharmacother. 2012 Oct:13(15):2157-70.

2. Banikarim C, Chacko MR, Kelder SH. Prevalence and impact of dysmenorrhea on Hispanic female adolescents. Arch Pediatr Adolesc Med. 2000;154:1226-9.

3. Parker MA, Sneddon AE, Arbon $P$. The menstrual disorder of teenagers (MDOT) study: determining typical menstrual patterns and menstrual disturbance in a large population-based study of Australian teenagers. BJOG. 2010;117:185-92.

4. Ozerdogan N, Sayiner D, Ayranci U. Prevalence and predictors of dysmenorrhea among students at a university in Turkey. Int J Gynaecol Obstet. 2009;107(1):39-43.

5. Unsal A, Tozun M, Ayrancı U, Orsal Ö. Connection between dysmenorrhea and depression among a group of turkish high school female students. Pak Med Sci. 2012;28(3):424-7.

6. Sundell G, Milsom I, Andersch B. Factors influencing the prevalence and severity of dysmenorrhoea in young women. British Journal of Obstetrics and Gynecology. 1990;97:588-94.

7. Unsal A, Ayranci U, Tozun M, Arslan G, Calik E. Prevalence of dysmenorrhea and its effect on quality of life among a group of female university students. Ups J Med Sci. 2010;115:138-45.

8. Bair MJ, Robinson RL, Katon W, Kroenke K. Depression and pain comorbidity: a literature review. Arch Intern Med. 2003;163:2433-45.

9. Van Houdenhove B, Onghena P. In: Robertson MM, Katona CLE, editors. Depression and physical illness. Chichester: Wiley; 1997. p. 465-97.

10. Bigal ME, Sheftell FD, Rapoport AM, Tepper SJ, Weeks R, Baskin SMMMPI Personality profiles in patients with primary chronic daily headache: a casecontrol study. Neurol Sci. 2003:24:103-10.

11. Dorn LD, Negriff S, Huang B, Pabst S, Hillman J, Braverman P, Susman EJ. Menstrual symptoms in adolescent girls: association with smoking, depressive symptoms, and anxiety. J Adolesc Health. 2009 March;44(3):237-43.

12. Varni JW, Seid M, Rode CA. The Peds QL: measurement model for the pediatric quality of life inventory. Med Care. 1999:37:126-39.

13. Memik NC, Ağaoğlu B, Coşkun A, Karakaya I. The validity and reliability of pediatric quality of life inventory in 8- 12 year old Turkish children. Turk. J Child Adolesc Ment Health. 2008;15:87-98.

14. Kovacs M. Rating scales to assess depression in school-aged children. Acta Paedopsychiatr. 1981;46:305-15.

15. Oy B. Cocuklar icin depresyon olceği: gecerlilik ve guvenirlik calışması. Turk Psikiyatri Derg. 1991;2:132-5. 
16. Spielberger CD, Gorsuch RL, Lushene RE. Manual for state-trait anxiety inventory. California: Consulting Psychologist Press; 1970.

17. Öner N. Le Compte A. Durumluk-Surekli Kaygı Envanteri El Kitabı: Boğazici Universitesi Yayımları Istanbul; 1985.

18. Robinson JC, Plichta S, Weisman CS, Nathanson CA, Ensminger M. Dysmenorrhea and use of oral contraceptives in adolescent women attending a family planning clinic. Am J Obstet Gynecol. 1992;166(2):578-83.

19. Aykut M, Günay O, Gün I, tuna R, Balcı E, Özdemir M, et al. the impact of some biological, socio-demographic and nutritional factors on the prevalence of dysmenorrhoea. Erciyes medical Journal. 2007;29(5):393-402.

20. Sundell G, Milsom I, Andersch B. Factors influencing the prevalence and severity of dysmenorrhoea in young women. Br J Obstet Gynaecol. 1990 Jul; 97(7):588-94.

21. Bahrami A, Sadeghnia H, Avan A, Mirmousavi SJ, Moslem A, Eslami S, et al. Eur J Obstet Gynecol Reprod Biol. 2017 Aug;215:224-9.

22. Gagua T, Tkeshelashvili B, Gagua D, McHedlishvili N. Assessment of anxiety and depression in adolescents with primary dysmenorrhea: a case-control study. J Pediatr Adolesc Gynecol. 2013 Dec;26(6):350-4.

23. Liang W, Zhang Y, Li H, Chu J, Qin Z, Lou L, et al. Personality and primary dysmenorrhea: a study using a five-factor model in Chinese university women. Archives of Neuropsychiatry. 2012;49:92-5.

24. Atasoy HT, Atasoy N, Unal AE, Emre U, Sumer M. Psychiatric comorbidity in medication overuse headache patients with preexisting headache type of episodic tension-type headache. Eur J Pain. 2005;9:285-91.

25. lacovides S, Avidon I, Bentley A, Baker FC. Reduced quality of life when experiencing menstrual pain in women with primary dysmenorrhea. Acta Obstet Gynecol Scand. 2014 Feb;93(2):213-7.

\section{Submit your next manuscript to BioMed Central and we will help you at every step:}

- We accept pre-submission inquiries

- Our selector tool helps you to find the most relevant journal

- We provide round the clock customer support

- Convenient online submission

- Thorough peer review

- Inclusion in PubMed and all major indexing services

- Maximum visibility for your research

Submit your manuscript at www.biomedcentral.com/submit 